Sonia Cristina de Magalhães Souza Fialho

\title{
Atividade de doença como principal fator de risco para osteonecrose no lúpus eritematoso sistêmico de diagnóstico recente
}

Tese apresentada à Faculdade de Medicina da Universidade de São Paulo para obtenção do título de Doutor em Ciências

Área de concentração: Reumatologia

Orientadora: Rosa Maria Rodrigues Pereira

SÃO PAULO

2006 


\section{AGRADECIMENTOS}

Ao meu querido marido Guilherme, "amor meu" e melhor amigo; companheiro e participante ativo nesta e em outras empreitadas; personagem sem o qual este projeto certamente nunca teria sido concluído.

Aos meus queridos pais: Sônia, Jairo, Olívia e Almir, exemplos de ser humano e de persistência, pessoas a quem devo grande parte do que sou hoje. Obrigada pelo incentivo, mas principalmente pelo apoio e amor incondicionais.

Ao meu querido irmão, Rafael, "orgulho meu", por todo amor, apoio e carinho; pelo olhar atento, tímido, porém vigilante, apesar da distância.

À minha querida irmã Livinha, pelo apoio incondicional a todos os meus projetos.

À Prof $^{\mathrm{a}}$ Eloísa, pela oportunidade de aperfeiçoamento técnico e aprendizado.

Ao Dr Célio, pelo carinho e por tudo que me ensinou sobre a vida e a Reumatologia.

À Prof ${ }^{a}$ Rosa, exemplo de profissional e ser humano, pela amizade e pelo apoio nos momentos difíceis.

Aos pacientes, que apesar de todas as dificuldades, continuam contribuindo para o melhor conhecimento médico-científico. 


\section{NORMALIZAÇÃO ADOTADA}

Esta tese esta de acordo com:

Referências: adaptado de International Committee of Medical Journals Editors (Vancouver)

Universidade de São Paulo. Faculdade de Medicina. Serviço de Biblioteca e Documentação. Guia de apresentação de dissertações, teses e monografias. São Paulo: Serviço de Biblioteca e Documentação; 2004.

Abreviaturas dos títulos dos periódicos de acordo com List of Journals Indexed in Index Medicus. 


\section{SUMÁRIO}

\section{Resumo \\ Summary}

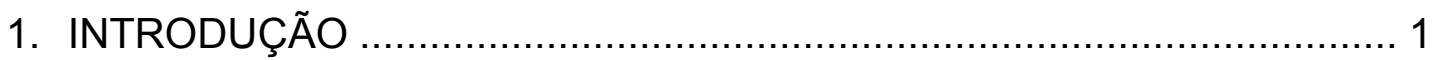

2. OBJETIVO

3. METODOLOGIA

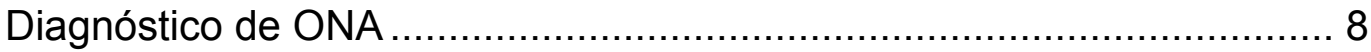

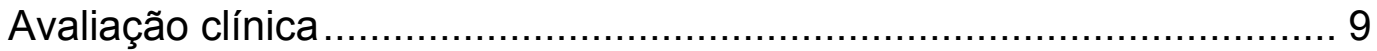

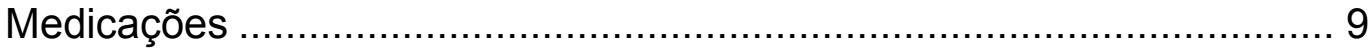

Avaliação da atividade da doença ................................................... 10

Avaliação laboratorial geral .......................................................... 10

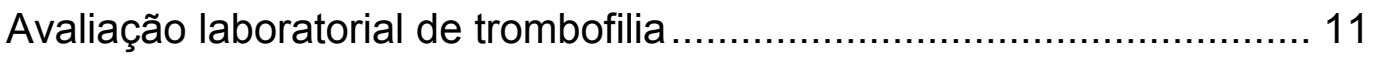

Avaliação da massa óssea .................................................................. 11

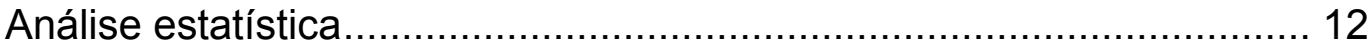

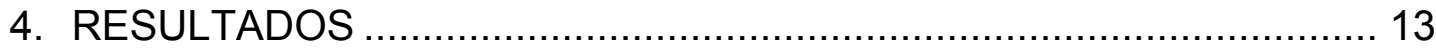

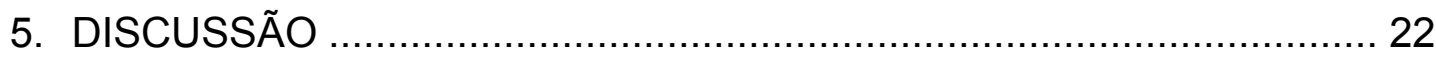

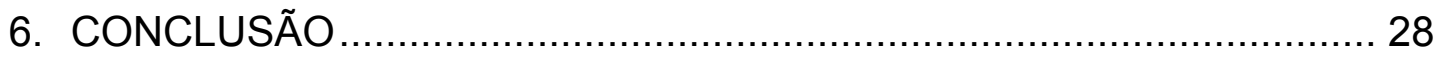

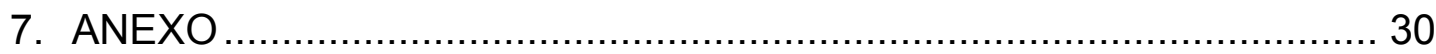

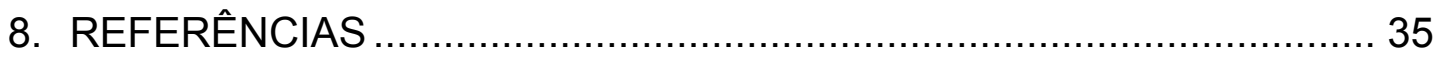

Apêndice 


\section{RESUMO}

Fialho SCMS. Atividade de doença como principal fator de risco para osteonecrose no Lúpus Eritematoso Sistêmico de diagnóstico recente [tese]. São Paulo: Faculdade de Medicina, Universidade de São Paulo; 2006. 41 p.

OBJETIVO. Identificar fatores preditivos para o desenvolvimento da osteonecrose (ONA) em pacientes com Lúpus Eritematoso Sistêmico (LES) de diagnóstico recente. METODOLOGIA. Quarenta e seis pacientes consecutivos, de uma coorte informatizada no ambulatório de LES do serviço de Reumatologia do Hospital das Clínicas de São Paulo, participaram deste protocolo que ocorreu entre julho de 2004 e julho de 2005. Os critérios de inclusão foram: pacientes do sexo feminino; menos de cinco anos de diagnóstico de LES; e idade maior que 18 anos. Todas as pacientes foram submetidas à ressonância nuclear magnética (RNM) dos quadris para o diagnóstico de ONA, independente da sintomatologia. Variáveis clínicas foram obtidas através de prontuários médicos, entrevista e exame clínico. Variáveis laboratoriais incluíram: lipoproteínas séricas, autoanticorpos, fatores trombofílicos e de hipofibrinólise. Densidade mineral óssea foi medida através da densitometria de dupla emissão de raios-X. Fraturas vertebrais foram investigadas através da realização de radiografias da coluna. RESULTADOS. A ONA foi encontrada em 10 das 46 pacientes. Idade, duração de doença e raça não diferiram entre pacientes lúpicas com e sem ONA. Comparações envolvendo as várias manifestações clínicas do LES, perfil lipoprotéico e de auto-anticorpos, freqüência de trombofilia e hipofibrinólise também não foram estatisticamente diferentes entre os grupos. A freqüência de pacientes com SLEDAI $\geq 8$ no ano anterior ao diagnóstico clínico de ONA foi significativamente maior $(60 \%)$ do que no grupo sem ONA considerando-se $\mathrm{o}$ ano anterior à entrada no estudo $(19,4 \%), p=0,011$. Corroborando com esse achado, a dose cumulativa de glicocorticóide (GC) utilizada no anterior ao diagnóstico de ONA foi maior quando comparada ao ano anterior à entrada no estudo $(p=0,045)$. Não foram observadas diferenças com relação aos dados densitométricos e radiográficos da coluna. $\mathrm{Na}$ análise multivariada somente o SLEDAI permaneceu como fator de risco independente para ONA $(O R=6,6, I C=1,07-$ 41,29, $p=0,042)$. CONCLUSÃO. Este estudo revela que a atividade de doença no ano anterior ao diagnóstico clínico de ONA é fator de risco preponderante para o desenvolvimento desta complicação no LES recente.

Descritores: 1.Osteonecrose 2.Lúpus eritematoso sistêmico/diagnóstico 3. Fatores de risco. 


\section{SUMMARY}

Fialho SCMS. Disease activity as a major risk factor for osteonecrosis in early systemic lupus erythematosus [thesis]. São Paulo: "Faculdade de Medicina, Universidade de São Paulo"; 2006. 41 p.

OBJECTIVE. To evaluate predictive factors for osteonecrosis (ON) development in patients with early Systemic Lupus Erythematosus (SLE). METHODS. Forty-six consecutive SLE patients from an electronic cohort in a Lupus Clinic from the Rheumatology Division in the University of São Paulo were enrolled on this study that occurred between July 2004 and July 2005. Inclusion criteria were female gender, age $\geq 18$ years-old and less than 5 years of disease duration. All patients underwent magnetic resonance imaging (MRI) of the hips for ON diagnosis irrespective of symptoms. Clinical variables were obtained through medical records, interview and physical examination. Laboratory variables were: serum lipoproteins, autoantibodies profile, trombophilia and hypofibrinolysis factors. Bone mineral density was acquired through dual energy x-ray absorptiometry. Vertebral fractures were investigated by spine X-rays. RESULTS. ON was found in 10 of 46 patients. Age, disease duration and race did not differ between patients with and without ON. The frequency of clinical features, lipoprotein and auto-antibodies profile and frequency of trombophilia and hypofibrinolysis were also alike in the two groups. Importantly, disease activity (frequency of patients with SLEDAI $\geq 8$ ) in the previous year of ON clinical diagnosis was significantly higher when compared to patients without $\mathrm{ON}$ in the previous year of study entrance $(60.0 \%$ vs. $19.4 \%, \quad p=0.011)$. Reinforcing this finding, glucocorticoid cumulative dose used in the previous year of $\mathrm{ON}$ diagnosis was also higher compared to SLE without ON in the previous year of study entrance $(p=0.045)$. Differences concerning the densitometric and radiographic data were not observed. Remarkably, in the multivariate analysis only SLEDAI remained as an independent risk factor for $\mathrm{ON}(\mathrm{OR}=6.6, \mathrm{Cl}=1.07-41.29, \mathrm{p}=$ 0.042 ). CONCLUSION. This study has clearly revealed that disease activity in the previous year of ON clinical diagnosis is the main predictor factor for the development of this complication in early SLE. 
A osteonecrose (ONA) é uma entidade clínica de patogênese pouco definida que se caracteriza por morte das células ósseas. Freqüentemente resulta em colapso da estrutura arquitetônica do osso levando à dor articular e perda da função ${ }^{(1)}$.

Um possível prejuízo circulatório para o osso afetado tem sido postulado como o denominador comum para todos os casos de ONA ${ }^{(2)}$. Inúmeras teorias foram propostas como prováveis causas desta interrupção circulatória na ONA não traumática.

Entre as doenças reumatológicas, a ONA está relacionada principalmente com o lúpus eritematoso sistêmico (LES). Grande parte dos estudiosos acredita que o uso dos glicocorticóides (GC) seria o fator de risco mais importante para o desenvolvimento de ONA em pacientes com LES ${ }^{(3-23)}$, no entanto, esta complicação também tem sido descrita em pacientes que nunca receberam tratamento com esta medicação ${ }^{(3,9,13,15)}$. Além disso, uma frequência muito menor de ONA tem sido relatada em outras condições clínicas que requerem utilização crônica de $G C^{(15)}$. Em contrapartida, fatores associados ao próprio LES têm sido propostos como possíveis fatores preditivos para o desenvolvimento da ONA. Estudos têm sugerido associação com alguns parâmetros clínicos como: atividade de doença ${ }^{(5,24)}$, vasculite $^{(8,10,16,25)}$, Fenômeno de Raynaud ${ }^{(4,10,18,25)}$, miosite ${ }^{(10,25)}$, artrite ${ }^{(20)}$, 
envolvimento do sistema nervoso central $(\mathrm{SNC})^{(9)}$, tromboflebite ${ }^{(8)}$, anticorpos antifosfolípides ou síndrome antifosfolípide ${ }^{(7-9,26-29)}$, trombofilia e hipofibrinólise $^{(8,12,21,30)}$.

Entre esses fatores, a atividade de doença é talvez o fator de mais difícil avaliação, visto que a maioria dos pesquisadores não utilizou instrumentos validados para este fim ${ }^{(5,24)}$, ou realizou a análise em momento diferente ao momento do real diagnóstico da ONA ${ }^{(13,31)}$.

Todavia, a interpretação desses trabalhos pode ter sido prejudicada pela não realização de ressonância nuclear magnética (RNM) em pacientes com ONA e/ou nos pacientes controles (3-16,20,21,24,26-28,30-32); e este fator, possivelmente, é o principal responsável pelos dados conflitantes obtidos nos diferentes estudos. De fato, o diagnóstico de ONA não pode ser baseado somente em sintomas clínicos, cintilografia óssea, ou imagens radiográficas convencionais ${ }^{(33-36)}$.

Além disso, os estudos que utilizaram RNM para o diagnóstico de ONA silenciosa, analisaram um número limitado de possíveis fatores de risco $^{(17-19,22,23)}$, o que prejudica uma visão geral do problema e consequentemente dificulta uma conclusão definitiva.

Com o objetivo de esclarecer esta questão, realizamos um estudo com uma extensa avaliação simultânea de vários possíveis fatores de risco importantes no LES de diagnóstico recente, em que a ausência de ONA foi confirmada através da realização de RNM. 
Identificar fatores preditivos para o desenvolvimento de ONA em pacientes com LES de diagnóstico recente. 
Desde 1999 um total de 870 pacientes com LES, que preenchem os critérios revisados do Colégio Americano de Reumatologia de 1997 para o LES (37), estão registrados e são regularmente acompanhados (em intervalos de 1-6 meses) pelo Serviço de Reumatologia do Hospital das Clínicas da Faculdade de Medicina da Universidade de São Paulo numa coorte informatizada. Todos os pacientes passam por uma história clínica e exame físico completos, baseado em um protocolo eletrônico que inclui dados demográficos, sintomas órgão-específicos, achados físicos, avaliações laboratoriais, Systemic Lupus Erythematosus Disease Activity Index (SLEDAI) ${ }^{(38)}$ e o índice de dano Systemic Lupus International Collaborating Clinics/ACR (SLICC) ${ }^{(39)}$. Entre julho de 2004 e julho de 2005, 50 pacientes consecutivos foram convidados para participar deste estudo. Dois pacientes recusaram-se a participar e 2 apresentavam história de claustrofobia e não puderam ser submetidos à RNM. Os critérios de inclusão foram: sexo feminino, idade acima de 18 anos e menos de 5 anos de duração do LES. As pacientes foram excluídas do estudo nas seguintes circunstâncias: fase aguda de trombose, gravidez, história prévia pessoal de alergia a contraste endovenoso, presença de doença infiltrativa na medula óssea, trauma recente de quadril, displasia congênita de quadril, gota, síndrome da imunodeficiência adquirida ou paciente sabidamente HIV 
positivo, proteinúria nefrótica ou insuficiência renal crônica, hemoglobinopatia, história de abuso de álcool, coagulopatia conhecida incluindo a síndrome do anticorpo antifosfolípide, uso de anticoagulante oral e radioterapia próxima à região do quadril.

Este estudo foi aprovado pela Comissão de Ética Médica da instituição e foi obtido consentimento informado de todas as participantes.

\section{Diagnóstico de ONA}

As pacientes foram submetidas à RNM dos quadris num aparelho de 1,5 T Medical Systems (General Electric) com as seguintes sequências: axial e coronal T2 com supressão de gordura, e T1, ambas com $4 \mathrm{~mm}$ de espessura e $1 \mathrm{~mm}$ de intersecção. Imagens contrastadas após a injeção de gadolinium-DTPA foram obtidas nas seguintes seqüências: coronal T2; sagital, coronal e axial T1 com supressão de gordura. Pacientes com exame sugestivo de ONA, ou com diagnóstico prévio confirmado por RNM anterior, foram comparadas com pacientes controles (sem evidência clínica ou de imagem de ONA). Todas as variáveis clínicas e laboratoriais (exceto na avaliação da trombofilia e hipofibrinólise) foram avaliadas no momento do diagnóstico clínico de ONA (sintomático), ou na entrada no estudo no caso dos pacientes controles. 


\section{Avaliação clínica}

O banco de dados foi revisado e complementado através de entrevista e exame físico em todas as pacientes elegíveis. Com relação ao domínio social e demográfico, as variáveis incluíram: etnia; idade; sexo; tabagismo; e etilismo. Com relação às variáveis clínicas, foram observados: duração da doença; índice de massa corpórea (IMC); dor típica de ONA; diagnóstico prévio de ONA; Cushing prévio ou atual; hipertensão arterial sistêmica; diabetes mellitus; dislipidemia; história prévia de fraturas (fraturas clínicas); história ginecológica e obstétrica; trombose prévia; vasculite; Síndrome de Sjogren; fenômeno de Raynaud; livedo reticular; e envolvimento do SNC.

\section{Medicações}

O registro do uso de medicações foi realizado de acordo com uso atual ou prévio, tempo de exposição, dose diária ou tempo percentual de exposição considerando a duração da doença para as seguintes medicações: drogas citotóxicas; difosfato de cloroquina; estatinas; cálcio; bisfosfonatos; estrógenos orais; e glicocorticóides (GC). O uso do GC foi adicionalmente registrado com as seguintes categorizações: dose na entrada do estudo ou no momento do diagnóstico clínico de ONA; dose máxima oral e em pulso; dose média diária; dose cumulativa total oral e em pulso; dose cumulativa no mês prévio e nos 3, 6, 12 e 24 meses prévios ao diagnóstico de ONA ou na entrada do estudo (grupo controle). 


\section{Avaliação da atividade da doença}

O SLEDAI foi registrado no momento de entrada no estudo (para pacientes controles), ou no momento do diagnóstico para o grupo com ONA; e nos dois anos anteriores às duas situações colocadas. Um escore $\geq 8$ foi arbitrariamente definido como um indicador de alto nível de atividade de doença. Para a análise estatística, a presença de um SLEDAI $\geq 8$, em pelo menos uma ocasião, no ano anterior ou no segundo ano anterior ao diagnóstico clínico de ONA ou à entrada no estudo, foi categorizada como positivo. O dano da doença foi acessado utilizando-se o SLICC que foi definido como ausente quando $=0$ e presente quando $>0$ (o item ONA foi removido para a obtenção do escore).

\section{Avaliação laboratorial geral}

Avaliação laboratorial no momento de diagnóstico de ONA ou na entrada do estudo (controles). Lipoproteínas séricas em jejum de 12 horas (colesterol total, lipoproteína de alta densidade - HDL, lipoproteína de baixa densidade - LDL, triglicerídeos) e auto-anticorpos. Os auto-anticorpos analisados foram: fator anti-nuclear (imunofluorescência indireta com células Hep-2); anti-DNA (imunofluorescência indireta com Crithidia.luciliae); anti-P (immunoblotting); anti-Ro/SSA (contra-imunoeletroforese); anti-La/SSB (contra-imunoeletroforese); anti-RNP e anti-Sm (hemaglutinação passiva); anticorpos anticardiolipina ( $\mathrm{ACL}$ ) IgG e IgM (ELISA); anticoagulante lúpico (Viperquik®). $\mathrm{O}$ anticoagulante lúpico $(\mathrm{AL})$ foi detectado seguindo as 
recomendações do Subcommittee on Lupus Anticoagulant/Antiphospholipid antibody of the Scientific and Standardization Committee of the International Society of Thrombosis and Haemostasis. Pacientes foram considerados como positivos para os antifosfolípides, se tivessem pelo menos dois resultados positivos (títulos moderados ou altos de $A C L$, ou $A L$ ) separados em pelo menos seis semanas.

\section{Avaliação laboratorial de trombofilia}

Esta avaliação foi realizada em todas as pacientes na entrada ao estudo. Proteína C (PC) e anti-trombina III (ATIII) foram analisadas através de ensaio cromogênico (Spectrolyse ${ }^{\circledR}$ ); tempo de protrombina (método de Quick), fator VIII e tromboplastina parcial ativada foram medidos por métodos de coagulação; proteína S (PS) foi medida por ELISA (Helena Laboratories®); Mutação dos fatores $\mathrm{V}$ e II foram acessados por reação de polimerase em cadeia (PCR); homocisteína foi medida por imunoensaio (IMX® system); e vitaminas B12 e ácido fólico foram determinadas através de quimiluminescência (Beckman Coulter®). Também foram analisados os níveis séricos de lipoproteína-a (Lp (a)), que têm sido associados à hipofibrinólise.

\section{Avaliação da massa óssea}

Densidade mineral óssea na coluna lombar, quadril, antebraço e corpo total foram medidos por DXA (densitometria de dupla emissão de 
fontes de raios-X), usando um aparelho Hologic QDR 2000 Plus. Todos os exames foram realizados na entrada do estudo. A composição corpórea também foi avaliada. Fraturas vertebrais foram diagnosticadas utilizando um método semi-quantitativo através da utilização de radiografias da coluna torácica e lombar (T4-L4) em perfil ${ }^{(40)}$.

\section{Análise estatística}

A distribuição de cada variável contínua foi examinada gráfica e estatisticamente para normalidade. Dados numéricos estão sumarizados como média e desvio-padrão (DP). Variáveis não normais foram comparadas utilizando o teste não paramétrico de Wilcoxon. Variáveis com distribuição normal foram comparadas utilizando o teste de " $\mathrm{t}$ " de Student. Variáveis categóricas foram comparadas através do teste de qui-quadrado. Alguns resultados foram categorizados como altos ou baixos de acordo com os valores de corte estabelecidos pelas técnicas específicas de cada caso. Análise de regressão logística multivariada foi utilizada para analisar a associação entre ONA (variável dependente) e variáveis de significância estatística considerando a análise univariada. Significância estatística foi fixada com $p<0,05$. Toda a análise estatística foi realizada através da utilização do software NCSS. 
ONA foi encontrada em 10 de 46 pacientes, $80 \%$ nos primeiros 2 anos de diagnóstico de LES. Dessas, 8 pacientes já tinham diagnóstico de ONA (confirmado por RNM) anteriormente à entrada no estudo; e 2 manifestaram sintomas durante o período do estudo. Trinta e seis pacientes não apresentaram evidência clínica ou de imagem de ONA, e foram desta forma, denominadas de grupo controle.

Dados demográficos de pacientes com e sem ONA revelaram dados semelhantes com relação à média de idade $(26,7 \pm 11,8$ vs. $32,11 \pm 11,7$ anos, $p=0,08)$, média de duração de doença $(17,6 \pm 6,72$ vs. $26,11 \pm 18,67$ meses, $p=0,55)$ e à freqüência de caucasianos $(50 \%$ vs. $44,4 \%, p=0,75)$.

Conforme ilustrado na tabela 1, foram observadas freqüências semelhantes entre os dois grupos de pacientes, no que diz respeito a dados clínicos como: vasculite, fenômeno de Raynaud, livedo reticular, envolvimento de SNC e síndrome de Sjögren. Além disso, sinais clínicos que são comumente associados ao uso de GC, tais como, aparência cushingóide, hipertensão arterial sistêmica e diabetes mellitus foram semelhantes nos grupos com e sem ONA. Corroborando com estes achados, parâmetros de composição corpórea (IMC, massa gorda e magra) também foram similares. Nenhuma das participantes tinha história de uso de álcool e o tabagismo (anos-maço) foi semelhante no grupo com $(4,5 \pm 12,5)$ e sem ONA $(4,5 \pm 10,3)$. 
Com relação à atividade de doença, a freqüência de pacientes com SLEDAI $\geq 8$ no ano anterior ao diagnóstico de ONA foi significativamente maior $(60 \%)$ quando comparados a pacientes sem ONA no ano anterior à entrada do estudo $(19,4 \%), p=0,011$. Por outro lado, a atividade de doença (SLEDAI $\geq 8$ ) na entrada do estudo ou no momento do diagnóstico clínico de ONA foi semelhante entre os grupos (10\% vs. $11,1 \%, p=1,00)$. Além disso, a freqüência de SLEDAI $\geq 8$ no período do $13^{\circ}-24^{\circ}$ meses que precederam ao diagnóstico de ONA ou à entrada ao estudo foi semelhante em pacientes com e sem ONA $(27,6 \%$ vs. $50 \%, p=0,23)$. SLICC não diferiu entre os grupos $(20 \%$ vs. $36 \%, p=0,33)$. 
Tabela 1: Características clínicas de pacientes lúpicas com e sem osteonecrose (ONA)

\begin{tabular}{|c|c|c|c|}
\hline & $\begin{array}{l}\text { LES com ONA } \\
\qquad(n=10)\end{array}$ & $\begin{array}{l}\text { LES sem ONA } \\
\qquad(n=36)\end{array}$ & $p$ \\
\hline Vasculite, \% & 30 & 22,2 & 0,61 \\
\hline Raynaud, \% & 30 & 58,3 & 0,11 \\
\hline Livedo, \% & 30 & 19,4 & 0,47 \\
\hline SNC, \% & 20 & 13,88 & 0,63 \\
\hline Síndrome de Sjögren, \% & 10 & 11,1 & 0,92 \\
\hline Cushing, \% & 100 & 82,3 & 0,31 \\
\hline Hipertensão, \% & 10 & 23,5 & 0,43 \\
\hline Diabetes, \% & 10 & 8,8 & 0,41 \\
\hline IMC $\left(\mathrm{Kg} / \mathrm{m}^{2}\right)$ & $24 \pm 3,47$ & $25 \pm 4,9$ & 0,89 \\
\hline Massa gorda (Kg) & $26,2 \pm 8,09$ & $25,86 \pm 21,68$ & 0,68 \\
\hline Massa magra (Kg) & $33,58 \pm 4,02$ & $34,22 \pm 6,11$ & 0,80 \\
\hline \multicolumn{4}{|l|}{ Atividade de Doença } \\
\hline SLEDAI atual $\geq 8, \%$ & 10 & 11,11 & 1,00 \\
\hline SLEDAI no ano anterior $\geq 8, \%$ & 60 & 19,44 & 0,011 \\
\hline $\begin{array}{l}\text { SLEDAI no segundo ano } \\
\text { anterior } \geq 8, \% \text { * }\end{array}$ & 27,59 & 50,0 & 0,23 \\
\hline \multicolumn{4}{|l|}{ Dano da Doença } \\
\hline SLICC $>0, \%^{\#}$ & 20 & 36,10 & 0,33 \\
\hline
\end{tabular}

Valores estão expressos como médias \pm DP ou percentuais; g: gramas.

${ }^{*} 13^{\circ}-24^{\circ}$ meses anteriores ao diagnóstico de ONA ou à entrada ao estudo (grupo controle). Dez pacientes não foram incluídos nesta análise visto que apresentavam apenas 1 ano de duração de doença (2 no grupo com ONA e 8 no grupo controle).

\# Item de ONA foi excluído. 
A extensa análise de tratamento do LES está ilustrada na tabela 2. Os 2 grupos foram similares no que diz respeito à dose cumulativa de GC no ano anterior, e nos 3 e 6 meses anteriores ao diagnóstico de ONA ou entrada no estudo. De forma semelhante, não foram encontradas diferenças com relação à dose cumulativa total (oral ou pulso), dose máxima diária oral ou de pulso e à dose média diária. Por outro lado, a dose cumulativa de GC no ano anterior ao diagnóstico de ONA foi significativamente maior quando comparado com a dose cumulativa no ano anterior à entrada no estudo (10.503 \pm 5.100 vs. $7.050 \pm 5.699 \mathrm{mg}, \mathrm{p}=0,045)$. No entanto, a análise da dose cumulativa do $13^{\circ}$ ao $24^{\circ}$ mês (anteriores ao diagnóstico de ONA ou à entrada no estudo) não revelou diferença estatística (4.470 \pm 4.428 vs. 5.017 $\pm 5.005 \mathrm{mg}, \mathrm{p}=0,75)$.

A freqüência de uso de imunossupressores (usados em qualquer momento) e de difosfato de cloroquina (uso atual) foi semelhante no LES com e sem ONA. Além disso, a diferença entre o tempo total de tratamento com a cloroquina não foi significativa $(12,5 \pm 9,2$ vs. $22,36 \pm 18,17$ meses, $p=0,19)$. Da mesma forma, a freqüência de uso atual de estatinas ou contraceptivos orais (ao diagnóstico ou entrada no estudo) foi semelhante entre os grupos (Tabela 2). 
Tabela 2: Tratamento nas pacientes lúpicas com e sem osteonecrose (ONA)

\begin{tabular}{|c|c|c|c|}
\hline & $\begin{array}{l}\text { LES com ONA } \\
\qquad(n=10)\end{array}$ & $\begin{array}{l}\text { LES sem ONA } \\
\qquad(n=36)\end{array}$ & $p$ \\
\hline \multicolumn{4}{|l|}{ Glicocorticosteróide } \\
\hline Mês anterior (mg) & $618 \pm 406$ & $790 \pm 1.164$ & 0,32 \\
\hline 3 meses anteriores $(\mathrm{mg})$ & $2.103 \pm 1.179$ & $1.816 \pm 1.773$ & 0,31 \\
\hline 6 meses anteriores (mg) & $4.713 \pm 2.428$ & $3.661 \pm 3.102$ & 0,16 \\
\hline Ano anterior (mg) & $10.503 \pm 5.100$ & $7.050 \pm 5.699$ & 0,045 \\
\hline $13^{\circ}-24^{\circ}$ mês anterior $(\mathrm{mg})$ & $4.470 \pm 4.428$ & $5.017 \pm 5.005$ & 0,75 \\
\hline Dose cumulativa total (mg) & $17.823 \pm 8.386$ & $20.924 \pm 10.772$ & 0,40 \\
\hline Dose cumulativa oral (mg) & $15.823 \pm 7.493$ & $18.008 \pm 9.825$ & 0,52 \\
\hline Dose cumulativa em pulsos (mg) & $2.000 \pm 1.882$ & $2.917 \pm 3.123$ & 0,55 \\
\hline Dose media oral (mg/dia) & $26 \pm 9,5$ & $23,76 \pm 11,51$ & 0,54 \\
\hline Dose máxima oral (mg/dia) & $59 \pm 23$ & $51 \pm 18$ & 0,65 \\
\hline Dose máxima em pulso (mg/dia) & $688 \pm 622$ & $712 \pm 619$ & 0,90 \\
\hline $\begin{array}{l}\text { Dose no diagnóstico de ONA ou } \\
\text { na entrada do estudo (mg/dia) }\end{array}$ & $20 \pm 14$ & $19 \pm 21$ & 0,42 \\
\hline Imunossupressor, \% & 70 & 66,6 & 1,00 \\
\hline Cloroquina - uso atual, \% & 80 & 86 & 0,64 \\
\hline Estatina - uso atual, \% & 0 & 16,7 & 0,13 \\
\hline Contraceptivo oral - uso atual, \% & 0 & 5,55 & 1,00 \\
\hline
\end{tabular}

Valores estão expressos como médias \pm DP ou percentagens; mg: miligramas. 
A tabela 3 ilustra que o perfil de lipoproteínas não diferiu entre os grupos com e sem ONA. A freqüência de auto-anticorpos (anti-DNA, antiRo/SSA, anti-La/SSB, anti-Sm, anti-RNP e anti-P) também foi semelhante (Tabela 3).

Tabela 3: Dados laboratoriais (no momento do diagnóstico de ONA ou na entrada do estudo) para as lipoproteínas e perfil de auto-anticorpos nas pacientes lúpicas com e sem ONA

\begin{tabular}{lccc} 
& $\begin{array}{c}\text { LES com ONA } \\
(\mathbf{n}=\mathbf{1 0})\end{array}$ & $\begin{array}{c}\text { LES sem ONA } \\
(\mathbf{n}=\mathbf{3 6})\end{array}$ & $\boldsymbol{p}$ \\
\hline Colesterol total $(\mathrm{mg} / \mathrm{ml})$ & $202,9 \pm 91$ & $180 \pm 42,3$ & 0,89 \\
LDL-colesterol $(\mathrm{mg} / \mathrm{ml})$ & $112,3 \pm 51,1$ & $99,72 \pm 31,9$ & 0,75 \\
HDL-colesterol $(\mathrm{mg} / \mathrm{ml})$ & $47,9 \pm 21,8$ & $55,5 \pm 17,5$ & 0,26 \\
Triglicerídeos $(\mathrm{mg} / \mathrm{ml})$ & $127,2 \pm 64,1$ & $126 \pm 60,9$ & 0,84 \\
Anti-DNA, \% & 30 & 42 & 0,50 \\
Anti-Ro, \% & 60 & 42 & 0,30 \\
Anti-P, \% & 10 & 28 & 0,24 \\
Anti-La, \% & 30 & 17 & 0,35 \\
Anti-Sm, \% & 20 & 33 & 0,42 \\
Anti-RNP, \% & 40 & 53 & 0,47 \\
\hline
\end{tabular}

Valores estão expressos como médias \pm DP ou percentagens. 
A avaliação de trombofilia revelou que a freqüência de positividade de ACL e AL e a elevação do fator VIII e homocisteína foram semelhantes nos grupos com e sem ONA (Tabela 4). Nenhum dos pacientes apresentava mutações dos fatores $\mathrm{V}$ de Leiden ou do gene da protrombina. Além disso, nenhuma diferença foi encontrada com relação à freqüência de deficiências de proteína C, S e anti-trombina III (Tabela 4).

Tabela 4: Dados laboratoriais (na entrada do estudo) para trombofilia e hipofibrinólise em pacientes lúpicas com e sem osteonecrose (ONA)

\begin{tabular}{lccc}
\hline & $\begin{array}{r}\text { LES com ONA } \\
(\mathbf{n = 1 0})\end{array}$ & $\begin{array}{c}\text { LES sem ONA } \\
(\mathbf{n = 3 6 )}\end{array}$ & $\boldsymbol{p}$ \\
\hline AL, \% & 0 & 8,33 & 0,59 \\
ACL IgG, \% & 10 & 2,77 & 0,39 \\
ACL IgM, \% & 10 & 2,77 & 0,39 \\
Fator VIII elevado, \% & 60 & 66 & 0,69 \\
Homocisteína elevada, \% & 40 & 41,6 & 0,92 \\
Lp (a) > 30mg/dl, \% & 50 & 44,11 & 0,74 \\
AT III deficiente, \% & 10 & 8,33 & 1,00 \\
PC deficiente, \% & 20 & 5,55 & 0,20 \\
PS deficiente, \% & 20 & 2,8 & 0,11 \\
\hline
\end{tabular}

Valores estão expressos como percentagens; ACL: anticorpos anticardiolipina; Lp (a): lipoproteína (a); AT III: anti-trombina III; PC: proteína C; PS: proteína S. 
A avaliação densitométrica demonstrou que pacientes com e sem ONA apresentavam massa óssea semelhante em quadril, antebraço, coluna e corpo total. Apenas 4 pacientes apresentaram fraturas radiográficas, todas elas no grupo sem ONA (Tabela 5).

Tabela 5: Densidade mineral óssea (DMO); fraturas clínicas e radiográficas em pacientes lúpicas com e sem osteonecrose (ONA)

\begin{tabular}{lccc}
\hline & $\begin{array}{c}\text { LES com ONA } \\
(\mathbf{n}=\mathbf{1 0})\end{array}$ & $\begin{array}{c}\text { LES sem ONA } \\
(\mathbf{n}=\mathbf{3 6})\end{array}$ & $\boldsymbol{p}$ \\
\hline DMO L1-L4, g/cm² & $0,930 \pm 0,122$ & $0,968 \pm 0,143$ & 0,44 \\
DMO colo femural, g/cm ${ }^{2}$ & $0,838 \pm 0,106$ & $0,801 \pm 0,139$ & 0,45 \\
DMO fêmur total, g/cm ${ }^{2}$ & $0,834 \pm 0,160$ & $0,859 \pm 0,141$ & 0,65 \\
DMO corpo total, g/cm & $0,976 \pm 0,151$ & $0,982 \pm 0,087$ & 0,87 \\
DMO rádio proximal, g/cm & $0,677 \pm 0,069$ & $0,654 \pm 0,064$ & 0,45 \\
DMO 1/3 distal rádio, g/cm & $0,395 \pm 0,07$ & $0,426 \pm 0,07$ & 0,25 \\
Fraturas clínicas, \% & 0 & 0 & $\mathrm{NA}$ \\
Fraturas radiográficas, \% & 0 & 11,43 & 1,00 \\
\hline
\end{tabular}

Valores estão expressos como médias \pm DP ou percentagens; NA: não é aplicável.

Após a análise multivariada (incluindo os dados de SLEDAl e dose cumulativa de GC no ano anterior ao diagnóstico de ONA ou entrada no estudo), identificamos que apenas o SLEDAI permaneceu como fator de risco independente para ONA $(\mathrm{OR}=6,6, \mathrm{IC}=1,07-41,29, \mathrm{p}=0,042)$. 
Este é o primeiro estudo que avaliou simultaneamente vários possíveis fatores de risco para ONA num grupo homogêneo de pacientes com LES, especialmente no que diz respeito à duração da doença e ao sexo.

A ONA parece ocorrer precocemente no LES ${ }^{(19,23,31)}$ e a escolha de inclusão de pacientes com menos de 5 anos de doença pode ter minimizado o efeito de variáveis de confusão envolvidas com o longo tempo de duração de doença. Além disso, uma vez que a predileção de ONA pelo sexo é controversa $^{(31,41,42)}$, o desenho de estudo incluiu somente pacientes do sexo feminino, o que excluiu essa possível influência do gênero.

Adicionalmente, foram excluídas todas as condições clínicas independentemente associadas com a ONA, tais como, gravidez, doenças infiltrativas da medula óssea, trauma recente em quadril, displasia congênita do quadril, gota, síndrome da imunodeficiência adquirida, hemoglobinopatias, história de abuso de álcool, radioterapia próxima à região de quadril, síndrome antifosfolípide e outras coagulopatias.

O diagnóstico de ONA foi definido por meio de RNM. ONA silenciosa pode ocorrer em $12 \%-35 \%$ de pacientes lúpicos ${ }^{(14,17,18,23,33)}$ e um método de screening de alta sensibilidade deve ser utilizado com o objetivo de assegurar a ausência de ONA nos pacientes controles. A RNM é o método de escolha para detecção precoce de alterações na medula óssea indicativas de ONA ${ }^{(34-36)}$ 
apresentando excelente correlação com a histologia (34-36). A grande variabilidade de resultados em estudos anteriores (no que diz respeito aos fatores de risco para ONA) poderia ser explicada pela utilização de outros procedimentos diagnósticos menos sensíveis tais como, sintomas clínicos, cintilografia óssea e/ou radiografias convencionais ${ }^{(3-14,16,20-24,26,27,30,32)}$.

O prejuízo circulatório, que pode levar à isquemia óssea, tem sido postulado como o denominador comum para todos os casos de ONA não traumática ${ }^{(2)}$. Alterações na hemostasia causam trombose e embolia e podem ter um papel neste processo. Entretanto, poucos estudos analisaram fatores de coagulação nos pacientes com LES e ONA ${ }^{(8,12,30)}$.

A associação entre ONA e os anticorpos antifosfolípides ainda é controversa $^{(8,22,32)}$, embora essa complicação tenha sido descrita em $20 \%$ dos casos de síndrome antifosfolípide primária ${ }^{(29)}$. Por esse motivo, excluímos pacientes portadores de síndrome antifosfolípide. Contudo, não foi encontrada associação entre ONA e a presença de anticorpos antifosfolípides. Analogamente, não observamos diferenças entre os grupos no que tange a alterações do fator VIII, homocisteína, PS, PC e anti-trombina III. Além disso, outras anormalidades procoagulantes hereditárias que têm sido associadas com ONA, tais como mutação do Fator $V$ de Leiden e do gene da protrombina, não foram encontradas ${ }^{(43,44)}$. Entretanto, devido ao tamanho da amostra neste estudo, não é possível tirar conclusões definitivas com relação a este mérito, principalmente quando se leva em consideração a raridade da ocorrência dessas alterações na população em geral. 
Desde que Dubois e Cozen ${ }^{(3)}$ descreveram o LES em associação com a ONA, pesquisadores têm tido dificuldades em diferenciar os possíveis efeitos deletérios causados pelo uso de GC, das manifestações inerentes à doença. De fato, um grande número de estudos encontrou que o uso de GC é um fator de risco importante para o desenvolvimento de ONA em paciente com LES ${ }^{(3-23)}$. Em acordo com estes estudos, detectamos que pacientes com ONA utilizaram maior dose cumulativa total de GC no ano anterior ao diagnóstico clínico de ONA. No entanto, não obtivemos os mesmos resultados quando comparamos a dose cumulativa total, considerando toda a duração do tratamento. De fato, estudos prévios demonstraram que a ONA é precocemente detectada após o início do tratamento com altas doses de GC, através da realização de RNM ${ }^{(19,45)}$. As comparações entre: a dose máxima diária de GC (oral ou em pulso), dose média diária e a dose no momento do diagnóstico foram semelhantes nos dois grupos. Os dados relacionados com os vários parâmetros de utilização de GC são conflitantes na literatura atual. A explicação mais plausível para essas discrepâncias é a definição imprecisa do tempo do desfecho, o que ocorre como conseqüência da utilização de metodologia diversa para o diagnóstico de ONA.

O uso crônico de GC leva a uma diminuição da taxa de formação óssea, secundária a osteoblastogênese e osteoclastogênese defeituosas. Além disso, há um aumento da taxa de apoptose de osteoblastos maduros e osteócitos, eventos que poderiam contribuir para a ocorrência de baixa densidade mineral óssea e ONA, observados nos pacientes que utilizam GC a longo prazo ${ }^{(46)}$. Entretanto, não observamos diferenças na densidade 
mineral óssea e freqüência de fraturas, entre os dois grupos de pacientes. Estudos em animais e humanos mostraram que possivelmente o aumento do conteúdo de gordura na medula óssea, paralelamente associado à elevação dos níveis de colesterol total induzido por GC, poderia ter um papel para o desenvolvimento de ONA ${ }^{(23)}$. O fato de não termos encontrado associação entre as frações de lipídeos no momento do diagnóstico de ONA não exclui a possibilidade desse efeito causal precedendo a complicação.

O aspecto mais relevante observado neste estudo foi o achado da importância da atividade de doença como um fator de risco primordial para a ocorrência de ONA. Mok et al, observaram que pacientes que requerem doses iniciais elevadas de GC para o controle da atividade de doença estão sob maior risco para o desenvolvimento de ONA ${ }^{(9)}$. Entretanto, estes autores não encontraram nenhuma associação com o SLEDAl, provavelmente pelo fato de que esta medida foi realizada de forma isolada. Analogamente, não encontramos diferenças estatísticas entre os grupos quando comparamos o SLEDAI no momento do diagnóstico de ONA (ou entrada no estudo). O mesmo ocorreu na análise do segundo ano anterior ao diagnóstico de ONA (ou entrada no estudo). Diferentemente, observamos que pacientes com ONA apresentaram maiores níveis de atividade de doença no ano anterior ao diagnóstico clínico de ONA. Ibanez et al, desenvolveram um índice de correção para a média de SLEDAI como uma forma de sumarizar a atividade de doença dentro do tempo de duração da mesma, porém não encontraram associação com ONA ${ }^{(31)}$. Todavia, como o tempo médio de seguimento nesse estudo foi de 6,9 anos, eventuais 
elevações na atividade de doença no ano anterior ao diagnóstico clínico de ONA podem ter sido atenuadas pelos outros anos em que a doença pode ter permanecido relativamente inativa.

Como reforço a este conceito, Colwell et al, não encontraram associação entre o uso de GC e o desenvolvimento de ONA em 1420 'quadris-anos' com 10 anos de seguimento de pacientes com asma ou $\operatorname{artrite}^{(47)}$. Poderíamos concluir que a incidência de ONA é baixa quando o uso de GC é o único fator de risco presente. 
A atividade de doença no ano anterior ao diagnóstico clínico da ONA é fator de risco importante para o desenvolvimento desta complicação no LES de diagnóstico recente. 
Anexo I

\section{HOSPITAL DAS CLÍNICAS}

DA

FACULDADE DE MEDICINA DA UNIVERSIDADE DE SÃO PAULO

TERMO DE CONSENTIMENTO LIVRE E ESCLARECIDO

(Instruções para preenchimento no verso)

\section{I - DADOS DE IDENTIFICAÇÃO DO SUJEITO DA PESQUISA OU RESPONSÁVEL LEGAL}

1. NOME DO PACIENTE

DOCUMENTO DE IDENTIDADE DATA NASCIMENTO.: .....................

ENDEREÇO:

BAIRRO:

CEP:.

$\mathrm{N}^{\mathrm{O}}$ SEXO: $M \quad F$

APTO:

CIDADE

TELEFONE:DDD(

..)...

2.RESPONSÁVEL LEGAL

NATUREZA(grau de parentesco, tutor, curador etc.)

DOCUMENTO DE IDENTIDADE :

DATA NASCIMENTO.: ....................

ENDEREÇO:......

BAIRRO:

CEP: .TELEFONE:DDD( SEXO: $M \quad F$

No

APTO:

CIDADE

..).

\section{II - DADOS SOBRE A PESQUISA CIENTÍFICA}

1.TÍTULO DO PROTOCOLO DE PESQUISA

AVALIAÇÃO DE OSTEONECROSE EM PACIENTES LÚPICOS

PESQUISADOR: Sonia Cristina de Magalhães Souza

CARGO/FUNÇÃO: Pós-graduanda

INSCRIÇÃO CONSELHO REGIONAL Nº 99.245

UNIDADE DO HCFMUSP: Reumatologia

2. AVALIAÇÃO DO RISCO DA PESQUISA:

\begin{tabular}{|c|c|c|}
\hline SEM RISCO & RISCO MÍNIMO & RISCO MÉDIO \\
\hline RISCO BAIXO & RISCO MAIOR & \\
\hline
\end{tabular}

(probabilidade de que o indivíduo sofra algum dano como consequência imediata ou tardia do estudo)

3.DURAÇÃO DA PESQUISA : 3 (três) anos 


\section{III - REGISTRO DAS EXPLICAÇÕES DO PESQUISADOR AO PACIENTE OU SEU REPRESENTANTE LEGAL SOBRE A PESQUISA CONSIGNANDO:}

\section{1. justificativa e os objetivos da pesquisa:}

Pacientes com lúpus e que tomam corticóide (meticorten), tem um risco grande de ter problema no osso do quadril (a osteonecrose, que é a morte do osso), e isto causa dor e com o passar do tempo, dificuldade para andar. Esse problema pode ser visto por um exame chamado: Ressonância Nuclear Magnética, antes mesmo que o paciente sinta dor ou qualquer outro problema. Assim, você está convidada para participar deste estudo que irá fazer Ressonância Magnética em pacientes com lúpus tomando corticóide para ver se você tem ou não esse problema nos ossos do quadril, e tentar descobrir porque isto aconteceu.

2. procedimentos que serão utilizados e propósitos, incluindo a identificação dos procedimentos que são experimentais:

1.Ressonância nuclear magnética nos dois quadris, para ver se você tem ou não osteonecrose. Neste exame a pessoa se deita numa mesa que se movimenta dentro de uma espécie de túnel, não há dor e o exame dura de 10 a 30 minutos;

2.Raio-X simples dos quadris para comparar com o exame de Ressonância Magnética;

3.Densitometria óssea em coluna e fêmur para ver se você tem osteoporose ou não, porque as pessoas que tem osteonecrose podem também ter osteoporose. Este exame não tem nenhum incômodo e dura de 10 a 30 minutos;

4.Exames de sangue que você realiza normalmente para saber se você tem atividade de doença e para saber se você tem problemas de coagulação (sangue grosso);

\section{3. desconfortos e riscos esperados:}

Para realização destes exames, você será internada na enfermaria de Reumatologia, no $8^{\circ}$ andar do Instituto Central do Hospital das Clínicas, por no máximo 3 dias. Será feita a coleta dos exames de sangue, a densitometria óssea, o raio- $X$ dos quadris, e o exame de Ressonância Nuclear Magnética. Você ficará internada para facilitar a realização da Ressonância que é muito difícil de ser marcada pelo ambulatório.

\section{4. benefícios que poderão ser obtidos:}

A ressonância nuclear magnética irá ver se você tem osteonecrose do osso do quadril, mesmo antes de você sentir dor, e isto vai ajudar o médico a tratar você mais rapidamente, antes que você comece a sentir dor ou a ter dificuldade para andar. A densitometria óssea poderá ver se você tem osteoporose, doença também muito freqüente nas pessoas que tem lúpus e usam meticorten e com isso também poder começar o tratamento. Os exames de sangue também poderão mostrar se você tem tendência para alteração da coagulação (trombose).

5. procedimentos alternativos que possam ser vantajosos para o indivíduo:

Não existem, porque a Ressonância Nuclear Magnética é o melhor exame para o diagnóstico precoce de osteonecrose. 
IV - ESCLARECIMENTOS DADOS PELO PESQUISADOR SOBRE GARANTIAS DO SUJEITO DA PESQUISA CONSIGNANDO:

1. acesso, a qualquer tempo, às informações sobre procedimentos, riscos e benefícios relacionados à pesquisa, inclusive para dirimir eventuais dúvidas.

2. liberdade de retirar seu consentimento a qualquer momento e de deixar de participar do estudo, sem que isto traga prejuízo à continuidade da assistência.

3. salvaguarda da confidencialidade, sigilo e privacidade.

4.disponibilidade de assistência no HCFMUSP, por eventuais danos à saúde, decorrentes da pesquisa.

5. viabilidade de indenização por eventuais danos à saúde decorrentes da pesquisa.

O paciente, ou responsável, terá acesso para questões sobre seus direitos como indivíduo do estudo, entrando em contato com a Comissão de Ética do Hospital das Clínicas, no telefone 3069-6442. Para qualquer pergunta sobre o estudo, entrar em contacto com a médica do estudo Dra Sonia Cristina de Magalhães Souza no telefone 3066-7213. A participação do paciente neste estudo é voluntária, podendo escolher não fazer parte deste estudo. Caso o paciente concorde em participar deste estudo, isto será mantido em sigilo. Esta pesquisa não envolve dano à saúde do paciente.

\section{INFORMAÇÕES DE NOMES, ENDEREÇOS E TELEFONES DOS RESPONSÁVEIS PELO ACOMPANHAMENTO DA PESQUISA, PARA CONTATO EM CASO DE INTERCORRÊNCIAS CLÍNICAS E REAÇÕES ADVERSAS.}

Dra. Sonia Cristina de Magalhães Souza-Faculdade de Medicina da USP-3 ${ }^{\circ}$ andar Reumatologia sala 3107

Fone: 3066-7213, 3066-7490

VI. OBSERVAÇÕES COMPLEMENTARES: 


\section{VII - CONSENTIMENTO PÓS-ESCLARECIDO}

Declaro que, após convenientemente esclarecido pelo pesquisador e ter entendido o que me foi explicado, consinto em participar do presente Protocolo de Pesquisa

São Paulo, de de 2004.

assinatura do sujeito da pesquisa ou responsável legal assinatura do pesquisador (carimbo ou nome Legível) 


\section{REFERÊNCIAS}


1. Mont MA, Carbone JJ. Fairbank AC. Core decompression versus nonoperative management for osteonecrosis of the hip. Clin Orthop Relat Res. 1996;324: 169-78.

2. Ficat RP. Idiopathic Bone Necrosis of the femoral head. $J$ Bone Joint Surg. 1985;67B: 3-9.

3. Dubois EL, Cozen L. Avascular (aseptic) bone necrosis associated with systemic lupus erythematosus. JAMA. 1960;174: 966-71.

4. Zizic TM, Marcoux C, Hungerford DS, Dansereau JV, Stevens MB. Corticosteroid therapy associated with ischemic necrosis of bone in systemic lupus erythematosus. Am J Med. 1985;79: 596-604.

5. Weiner ES, Abeles M. Aseptic necrosis and glucocorticosteroids in systemic lupus erythematosus: a reevaluation. J Rheumatol. 1989;16: 604-8.

6. Massardo L, Jacobelli S, Leissner M, Gonzalez M, Villarroel L, Rivero S. High-dose intravenous methylprednisolone therapy associated with osteonecrosis in patients with systemic lupus erythematosus. Lupus. 1992;1: 401-5.

7. Migliaresi S, Picillo U, Ambrosone L, Di Palma G, Mallozzi M, Tesone ER, et al. Avascular osteonecrosis in patients with SLE: relation to corticosteroid therapy and anticardiolipin antibodies. Lupus. 1994;3: 37-41.

8. Mont MA, Glueck CJ, Pacheco IH, Wang P, Hungerford DS, Petri M. Risk factors for osteonecrosis in systemic lupus erythematosus. J Rheumatol. 1997;24: 654-62. 
9. Mok CC, Lau CS, Wong RW. Risk factors for avascular bone necrosis in systemic lupus erythematosus. Br J Rheumatol. 1998;37: 895-900.

10. Zizic TM, Hungerford DS, Stevens MB. Ischemic bone necrosis in systemic lupus erythematosus. The early diagnosis of ischemic necrosis of bone. Medicine. 1980;59: 134-42.

11. Abeles M, Urman JD, Rothfield NF. Aseptic necrosis of bone in systemic lupus erythematosus. Relationship to corticosteroid therapy. Arch Inter Med. 1978;138: 750-4.

12. Sheik JS, Retzinger GS, Hess EV. Association of osteonecrosis in systemic lupus erythematosus with abnormalities of fibrinolysis. Lupus. 1998;7: 42-8.

13. Rascu A, Manger K, Kraetsch HG, Kalden JR, Manger B. Osteonecrosis in systemic lupus erythematosus, steroid-induced or a lupus-dependent manifestation? Lupus. 1996;5: 323-7.

14. Klippel JH, Gerberg LH, Pollak L, Decker JL. Avascular necrosis of bone in systemic lupus erythematosus: Silent symmetric osteonecrosis. Am J Med. 1979;67: 83-7.

15. Zizic TM. Avascular necrosis of bone. Curr Opin Rheumatol. 1990;2: 26-37.

16. Bergstein JM, Wiens C, Fish AJ, Vernier RL, Michael A. Avascular necrosis of bone in systemic lupus erythematosus. J Pediatr. 1974;85: $31-5$.

17. Nagasawa K, Tsukamoto $H$, Tada $Y$, Mayumi T, Satoh H, Onitsuka H, et al. Imaging study on the mode of development and changes in avascular necrosis of the femoral head in systemic lupus erythematosus: long term observations. Br J Rheumatol. 1994;33: 343-7. 
18. Aranow C, Zelicof S, Leslie D, Solomon S, Barland P, Norman A, et al. Clinically occult avascular necrosis of the hip in systemic lupus erythematosus. J Rheumatol. 1997;24: 2318-22.

19. Oinuma K, Harada Y, Nawata Y, Takabayashi K, Abe I, Kamikawa K, et al. Osteonecrosis in patients with systemic lupus erythematosus develops very early after starting high dose corticosteroid treatment. Ann Rheum Dis. 2001;60: 1145-8.

20. Gladman DD, Urowitz MB, Chaudry-Ahluwalia V, Hallet DC, Cook RJ. Predictive factors for symptomatic osteonecrosis in patients with systemic lupus erythematosus. J Rheumatol. 2001;28: 761-5.

21. Nagasawa K, Ishii YI, Mayumi T, Tada Y, Ueda A, Yamauchi $Y$, et al. Avascular necrosis of bone in systemic lupus erythematosus: possible role of haemostatic abnormalities. Ann Rheum Dis. 1989;48: 672-6.

22. Houssiau FA, Toukap NA, Depresseux G, Maldague BE, Malghem J, Devogelaer JP, et al. Magnetic resonance-imaging-detected avascular osteonecrosis in systemic lupus erythematosus: lack of correlation with antiphospholipid antibodies. Br J Rheumatol. 1998;37: 448-53.

23. Nagasawa K, Tada $Y$, Koarada S, Horiuchi T, Tsukamoto H, Murai K, et al. Very early development of steroid-associated osteonecrosis of femoral head in systemic lupus erythematosus: prospective study by MRI. Lupus. 2005;14: 385-90.

24. Nilsen KH. Systemic lupus erythematosus and avascular bone necrosis. N Z Med J. 1977;8: 472-5.

25. Hungerford DS, Zizic TM. The treatment of ischemic necrosis of bone in systemic lupus erythematosus. Medicine. 1980;59: 143-8.

26. Abeles M, Weiner ES, Parke A, Wilson D. The association of osteonecrosis in SLE with anticardiolipin antibodies. Arthritis Rheum. 1991;34 (suppl): R39. 
27. Asherson RA, Liote F, Page B, Meyer O, Buchanan N, Khamashta MA, et al. Avascular necrosis of bone and antiphospholipid antibodies in systemic lupus erythematosus. J Rheumatol. 1993;20: 284-8.

28. Seleznic MJ, Silveira LH, Espinoza LR. Avascular necrosis associated with anticardiolipin antibodies. J Rheumatol. 1991;18: 1416-7.

29. Tektonidou MG, Malagari K, Vlachoyiannopoulos PG, Kelekis DA, Moutsopoulos HM. Asymptomatic avascular necrosis in patients with primary antiphospholipid syndrome in the absence of corticosteroid use: a prospective study by resonance imaging. Arthritis Rheum. 2003;48: 732-6.

30. Jones LC, Mont MA, Le TB, Petri M, Hungerford DS, Wang P, Glueck CJ. Progoagulants and Osteonecrosis. J Rheumatol. 2003;30: 783-91.

31. Ibanez D, Gladman DD, Urowitz MB. Adjusted mean Systemic Lupus Erythematosus Disease Activity Index-2K is a predictor of outcome in SLE. J Rheumatol. 2005;32: 824-7.

32. Mok MY, Farewell VT, Isenberg DA. Risk factors for avascular necrosis of bone in patients with systemic lupus erythematosus: is there a role for antiphospholipid antibodies? Ann Rheum Dis. 2000;59: 462-7.

33. Halland AM, Klemp P, Botes D, Van Heerden BB, Loxton A, Scher AT. Avascular necrosis of the hip in systemic lupus erythematosus: the role of magnetic resonance imaging. Br J Rheumatol. 1993;32: 972-6.

34. Kalunian KC, Hahn BH, Bassett L. Magnetic resonance imaging identifies early femoral head ischemic necrosis in patients receiving systemic glucocorticoid therapy. J Rheumatol. 1989;16: 959-63.

35. Mitchell DG, Rao VM, Dalinka MK, Spritzer CE, Alavi A, Steinberg ME, et al. Femoral head avascular necrosis: correlation of MR imaging, radiographic staging, radionuclide imaging, and clinical findings. Radiol. 1987;162: 709-15. 
36. Markisz JA, Knowles RJ, Altchek DW, Schneider R, Whalen J, Cahill PT. Segmenal patterns of avascular necrosis of the femoral heads: early detection with MR imaging. Radiol. 1987;162: 717-20.

37. Hochberg MC. Updating the American College of Rheumatology revised criteria for the classification of systemic lupus erythematosus [letter]. Arthritis Rheum. 1997;40: 1725.

38. Bombardier C, Gladman DD, Urowitz MB, Caron D, Chang $\mathrm{CH}$, and the Committee on Prognosis Studies in SLE. Derivation of the SLEDAI: a disease activity index for lupus patients. Arthritis Rheum. 1992;35: 630-40.

39. Gladman D, Ginzler E, Goldsmith C, Fortin P, Liang M, Urowitz M, et al. The development and initial validation of the Systemic Lupus International Collaborating Clinics/American College of Rheumatology damage index for systemic lupus erythematosus. Arthritis Rheum. 1996;39: 363-9.

40. Genant HK. Radiographic assessment of the effects of intermittent cyclical treatment with etidronate. In: Christiasen C, Overgaard $\mathrm{K}$ (eds). Osteoporosis. Copenhagen: Osteopress ApS; 1990. p.2047-54.

41. Talamo G, Angtuaco E, Walker RC, Dong L, Miceli MH, Zangari M, et al. Avascular necrosis of femoral and/or humeral heads in multiple myeloma: results of a prospective study of patients treated with dexamethasone-based regimes and high-dose chemotherapy. J Clin Oncol. 2005;23(22): 5217-23.

42. Schulte CM, Beelen DW. Avascular osteonecrosis after allogenic hematopoietic stem-cell transplantation: diagnosis and gender matter. Transplantation. 2004;78(7): 1055-63.

43. Bjorkman A, Burtscher IM, Svensson PJ, Hillarp A, Besjakov J, Benoni G. Factor V Leiden and prothrombin 20210A gene mutation and osteonecrosis of the knee. Arch Orthop Trauma Surg. 2005;125: 51-5. 
44. Bjorkman A, Svensson PJ, Hillarp A, Burtscher IM, Runow A, Benoni G. Factor $\mathrm{V}$ Leiden and prothrombin gene mutation: risk factors for osteonecrosis of femoral head in adults. Clin Orthop Relat Res. 2004;425: 168-72.

45. Sakamoto M, Shimizu K, Lida S, Akita T, Moriya H, Nawata $Y$. Osteonecrosis of the femoral head: a prospective study with MRI. J Bone Joint Surg Br. 1997;79: 213-9.

46. Weinstein RS, Jilka RL, Parfitt AM, Manolagas SC. Inhibition of Osteoblastogenesis and Promotion of Apoptosis of Osteoblasts and Osteocytes by Glucocorticoids: Potential Mechanisms of Their Deleterious Effects on Bone. J Clin Invest. 1998;102(2): 274-282.

47. Colwell CW Jr, Robinson CA, Stevenson DD, Vint VC, Morris BA. Osteonecrosis of the femoral head in patients with inflammatory arthritis or asthma receiving corticosteroid therapy. Orthopedics. 1996;19(11): 941-6. 


\section{ARTIGO ENVIADO PARA PUBLICAÇÃO}

\section{Disease Activity as a Major Risk Factor for Osteonecrosis in Early Systemic Lupus Erythematosus}

Sonia CMS Fialho, MD ${ }^{1}$, Eloisa Bonfá, MD, PhD ${ }^{1}$, Luis F Vitule, $\mathrm{MD}^{2}$, Elbio D'Amico, MD, $\mathrm{PhD}^{3}$, Valeria Caparbo ${ }^{1}$, Sandra Gualandro, $\mathrm{MD}, \mathrm{PhD}^{3}$, Rosa MR Pereira, MD, $\mathrm{PhD}^{1}$

Rheumatology ${ }^{1}$ and Hematology ${ }^{3}$ Division and Radiology Department ${ }^{2}$, School of Medicine, University of São Paulo, São Paulo, Brazil

Grant support: CNPq \# 304756/2003-2 (to EB)

Address correspondence and reprint request to Rosa M.R. Pereira, MD, PhD, Faculdade de Medicina USP, Reumatologia, Avenida Dr Arnaldo, $455-3^{\circ}$ andar- Reumatologia, sala 3107, São Paulo SP, 01246-000 Brazil.

E-mail: rosamariarp@yahoo.com, reumato@usp.br

Running Title: Osteonecrosis in SLE 
SUMMARY

Objective. Identify possible risk factors for osteonecrosis in a homogenous group of early SLE.

Methods. 46 consecutive SLE patients ( $<5$ years duration) followed at the Lupus Clinic, were enrolled between 2004-2005. An extensive clinical and laboratory evaluation using a standard electronic protocol established since 1999, including osteonecrosis symptoms and appropriate magnetic resonance imaging (MRI), were carried out at 1-6 months intervals. All other asymptomatic for osteonecrosis patients at study entry underwent MRI.

Results. Osteonecrosis confirmed by MRI was found in 10 of 46 patients (22\%). Age, disease duration, clinical vascular features, the frequency of thrombophilia and hypofibrinolysis factors and the lipoprotein profile were comparable in patients with and without osteonecrosis $(p>0.05)$. Remarkably, the frequency of patients with SLEDAI $\geq 8$ in the previous year of osteonecrosis clinical diagnosis was significantly higher when compared to patients without this manifestation $(60.0 \%$ vs. $19.4 \%, p=0.011)$, supported by the higher glucocorticoid cumulative dose in the same period $(p=0.045)$. In contrast, these two parameters evaluated in $13^{\text {th }}-24^{\text {th }}$ months preceding osteonecrosis diagnosis was similar in patients with and without osteonecrosis $(p>0.05)$. In the multivariate analysis only SLEDAI remained as an independent risk factor for osteonecrosis $(O R=6.6, C I=1.07-41.29, p=$ 0.042).

Conclusion. Disease activity in the previous year of osteonecrosis clinical diagnosis is the main predictor factor for the development of this complication in early SLE.

Keywords: systemic lupus erythematosus; osteonecrosis; SLEDAI; disease activity. 


\section{INTRODUCTION}

Osteonecrosis is a clinical entity of unclear pathogenesis characterized by death of bone marrow and trabecular bone. It often results in the collapse of the architectural bone structure, leading to joint pain, bone destruction, and loss of function (1). Circulatory impairment to the affected bone has been postulated to be the common denominator for all cases of osteonecrosis (2).

Among the rheumatic diseases, osteonecrosis is strongly associated with systemic lupus erythematosus (SLE). Most investigators have found glucocorticoid (GC) use to be a major risk factor for osteonecrosis in SLE (323), however this complication has also been reported in lupus patients who have never received therapy with this drug $(3,9,13,15)$. Moreover, a significant lower frequency of osteonecrosis has been reported in other clinical conditions requiring chronic corticosteroid therapy (15).

Alternatively, disease associated factors have been proposed to enhance the risk for osteonecrosis development, such as: disease activity $(5,24)$, vasculitis $(8,10,16,25)$, Raynaud's phenomenon $(4,10,18,25)$, thrombophlebitis (8), antiphospholipid antibodies or syndrome (7-9,26-29), thrombophilia and hypofibrinolysis $(8,12,21,30)$.

Among those, disease activity is perhaps the most difficult to elucidate since most studies have not used standard instruments of measurement 
$(5,24)$ and more importantly they have not evaluated flares at the time or close to the osteonecrosis clinical onset $(13,31)$.

In addition, the interpretation of all these risk factors has been hampered by the lack of magnetic resonance imaging (MRI) in patients and/or controls groups $(3-16,20,21,24,26-28,30-32)$. In fact, clinical symptoms, bone scintigraphy, and conventional radiographic images (3336) are not as sensitive to diagnose early osteonecrosis. Moreover, the simultaneous analysis of a limited number of potential risk factors associated with osteonecrosis $(17-19,22,23)$ in previous reports, may have hampered an overall view of the problem and consequently precludes a definitive conclusion.

We therefore have evaluated simultaneously several risk factors for osteonecrosis in early SLE patients in whom diagnosis was confirmed by MRI. 


\section{PATIENTS AND METHODS}

Since 1999, 870 patients with SLE who fulfilled the American College of Rheumatology 1997 revised criteria for SLE (37) had been registered and followed at the Lupus Outpatient Clinic, University of São Paulo. The standard electronic protocol was carried out at 1-6 months intervals and consisted of an extensive clinical and laboratory evaluation, including those relevant for this study such as, osteonecrosis symptoms and appropriate magnetic resonance imaging (MRI), Systemic Lupus Erythematosus Disease Activity Index (SLEDAI) (38) and glucocorticoid therapy. All information collected on these patients is entered into a database.

Between July 2004 and July 2005, forty six consecutive patients followed in this cohort were enrolled for the present study according to the following criteria. The inclusion criteria were female gender, age $\geq 18$ yearsold and less than 5 years of disease duration. The exclusion criteria were previous history of endovenous contrast allergy or claustrophobia, acute thrombosis, pregnancy, current nephrotic proteinuria or renal chronic insufficiency, HIV positive or acquired immunodeficiency syndrome, hemoglobinopathy, known coagulopathy (including the antiphospholipid syndrome), recent trauma or radiotherapy next to the hip region, congenital hip dysplasia, infiltrative bone marrow disease, previous or current history of alcohol abuse, and oral anticoagulant use. This study received institutional review, and informed consent was obtained for each participant. 
All 46 patients underwent MRI of both hips on a 1,5 T Medical Systems (General Electric) with the following sequences: axial and coronal T2-weighted fat suppressed, and T1-weighted, both with $4 \mathrm{~mm}$ section thickness, and $1 \mathrm{~mm}$ intersection gap. Contrast-enhanced images were obtained after administration of gadolinium-DTPA and images were acquired with coronal T2-gradient, and sagital, coronal and axial T1 with fat suppression. Patients with known osteonecrosis diagnosis confirmed by previous MRI at study entry were not exposed to a new examination.

Lupus patients with clinical osteonecrosis confirmed by MRI were subsequently compared to the control group (patients without clinical and MRI evidence of osteonecrosis) regarding clinical and laboratorial parameters as well as therapies formerly reported to be associated with osteonecrosis. Disease activity, Raynaud's phenomenon, vasculitis, livedo reticularis, thrombophilia and fibrinolysis factors, lipoprotein profile (12 hour fasting serum total cholesterol, high-density lipoprotein-HDL, low density lipoprotein-LDL, triglycerides), drugs (corticosteroid, chloroquine and cytotoxic) were therefore evaluated as possible associated factors. All clinical, laboratorial and therapy parameters were evaluated at osteonecrosis clinical onset or at study entry for the control group, except when otherwise stated.

Disease activity was assessed by SLEDAI (38) and a score $\geq 8$ was arbitrarily defined as an active disease. Disease damage was determined 
using SLICC damage index (39) which was categorized as absent when $=0$ and present when $>0$ (osteonecrosis was not included for the SLICC score). Laboratory variables were determined according to the routine examination and included: 12 hour fasting serum lipoproteins (total cholesterol, high-density lipoprotein-HDL, low density lipoprotein-LDL, triglycerides); autoantibodies [anti-nuclear antibodies, anti-dsDNA, anti-Sm anticardiolipin antibodies (ACL) IgG and IgM and lupus anticoagulant (LA)]. The later was detected following the recommendations of the Subcommittee on Lupus Anticoagulant/Antiphospholipid antibody of the Scientific and Standardization Committee of the International Society of Thrombosis and Haemostasis.

Laboratory thrombophilic factors were performed after enrollment for all patients. Protein C (PC) and anti-thrombin III (ATIII) were measured by chromogenic assay (Spectrolyse $®$ ); prothrombin time (Quick method), factor VIII and activated partial thromboplastin time were measured by coagulation methods; free protein S (PS) was measured by an enzyme linked immunosorbent assay (Helena Laboratories $($ )); factors $V$ and II mutations were assessed by the polymerase chain reaction; homocysteine was measured by polarized fluorescence immunoassay (IMX® system); vitamins B12 and folic acid were determined by chemiluminescence (Beckman Coulter ()$)$. We also analyzed serum lipoprotein-a $(\operatorname{Lp}(a))$, which has been reported to be associated with hypofibrinolysis. 
Statistical analysis. The distribution of each continuous variable was examined graphically and statistically for normality. Numerical data are summarized as the mean and standard deviation (SD). Variables not normally distributed were compared using the Wilcoxon nonparametric test for differences. Variables normally distributed were compared using Student's test. Categorical data among groups were compared by the chisquare statistic. Some results were evaluated according to the established normal values and were subsequently ranked as elevated or depressed. Multivariate logistic regression was used to analyze association between osteonecrosis (dependent variable) and variables found to be statistically significant on the univariate analysis. Statistical significance was set at $p<$ 0.05. All statistical analysis was performed using NCSS software. 


\section{RESULTS}

Osteonecrosis was found in 10 out of 46 patients (22\%), 80\% in the first two years of lupus diagnosis (ACR criteria). These patients comprised the osteonecrosis group (ON group), eight of them had osteonecrosis diagnosis confirmed by MRI before study enrollment and two had the clinical manifestation confirmed by MRI during the study period. The other 36 patients without clinical symptoms/MRI osteonecrosis were denominated the CONTROL group.

Demographic data of osteonecrosis patients and SLE controls revealed a similar mean age ( $26.7 \pm 11.8$ vs. $32.11 \pm 11.7$ years, $\mathrm{p}=0.08)$, mean disease duration $(17.6 \pm 6.72$ vs. $26.11 \pm 18.67$ months, $p=0.55)$ and frequency of Caucasians (50 vs. $44.4 \%, p=0.75$ ).

A similar frequency of clinical features, such as, vasculitis, Raynaud's phenomenon, livedo reticularis was observed between the two groups as illustrated in Table 1. Moreover, clinical signs that are associated with steroid therapy, including a Cushing appearance and BMI were comparable in both groups. In addition, none of the individuals had a history of alcohol use and the use of tobacco (pack-years) was similar in patients with (4.5 \pm 12.5) and without osteonecrosis (4.9 \pm 10.2$)$.

Regarding disease activity, the frequency of patients with SLEDAI $\geq 8$ in the previous year of osteonecrosis clinical diagnosis was significantly higher when compared to patients without osteonecrosis in the previous year of study entry (60 vs. $19.4 \%, p=0.01$ ). In contrast, the frequency of 
patients with SLEDAI $>8$ at the osteonecrosis clinical diagnosis was alike the control group at study entry (10 vs. $11 \% . p=1.00)$. Moreover, the frequency of patients with SLEDAI $>8$ at the remote $\left(13^{\text {th }}-24^{\text {th }}\right.$ preceding months) osteonecrosis clinical diagnosis was comparable to the control group in the same period ( 28 vs. $50 \%, p=0.23$ ). The frequency of SLICC damage index greater than zero did not differ between groups as well (20 vs. $36 \%$, $\mathrm{p}=0.33)$.

The extensive analysis regarding GC revealed a significant higher cumulative dose during the previous year in ON group compared CONTROL group $(10,503 \pm 5,100$ vs. $7,050 \pm 5,699 \mathrm{mg}, \mathrm{p}=0.040)$. In contrast, the prior $13^{\text {th }}-24^{\text {th }}$ months GC cumulative doses $(4,470 \pm 4,428$ vs. $5,017 \pm$ $5,005 \mathrm{mg}, \mathrm{p}=0.75)$, the total GC cumulative doses $(17,823 \pm 8,386$ vs. $20,924 \pm 10,772 \mathrm{mg}, \mathrm{p}=0.40)$ and the GC doses at osteonecrosis clinical onset (ON group)/entry (CONTROL group) $(20 \pm 14$ vs. $19 \pm 21, p=0.42)$ were alike in both groups (Table 2).

The frequency of cytotoxic drugs (ever used) and chloroquine use at osteonecrosis onset (ON group)/entry (CONTROL group) was comparable $(p>0.05)$ (Table 2). Likewise, the frequency of oral contraceptive at osteonecrosis onset (ON group)/entry (CONTROL group) (0 vs. 5.5\%, $\mathrm{p}=1.0$ ) was similar in both groups (Table 2 ).

Table 3 illustrates that lipoprotein profile at ON clinical diagnosis (ON group) and study entry (CONTROL group) did not distinguish patients with and without ON since the levels of total cholesterol (202.9 \pm 91.0 vs. 180.0 
$\pm 42.3 \mathrm{mg} / \mathrm{ml}, \mathrm{p}=0.89), \mathrm{LDL}-$ fraction $(112.3 \pm 51.1$ vs. $99.7 \pm 31.9 \mathrm{mg} / \mathrm{dl}$, $\mathrm{p}=0.75)$, HDL-fraction $(47.9 \pm 21.8$ vs. $55.5 \pm 17.5 \mathrm{mg} / \mathrm{dl}, \mathrm{p}=0.26)$, triglycerides $(127.2 \pm 64.1$ vs. $126.0 \pm 60.9 \mathrm{mg} / \mathrm{dl}, \mathrm{p}=0.84)$ were comparable. The frequency of autoantibodies (anti-dsDNA, anti-Ro/SSA, anti-La/SSB, anti-Sm, anti-RNP and anti-P) was also alike in both groups (data not shown).

Likewise evaluation of thrombophilia at study entry for both groups revealed that the frequency of lupus anticoagulant, anticardiolipin antibodies, high factor VIII, high homocysteine and high LPL were comparable in ON and CONTROL groups (Table 4). None of the SLE patients presented factor $\mathrm{V}$ or II mutations. Also no differences in the frequency of low protein $\mathrm{C}$, low protein $\mathrm{S}$ and anti-thrombin III deficiency was observed in both groups (Table 4).

Multivariate analysis was performed (including SLEDAI and cumulative GC dose in the previous year of osteonecrosis clinical diagnosis or study entry) and only SLEDAI remained as an independent risk factor for osteonecrosis ( $\mathrm{OR}=6.6, \mathrm{CI}=1.07-41.29, \mathrm{p}=0.042)$. 


\section{DISCUSSION}

Our study demonstrated that disease activity is a major risk factor for osteonecrosis development in female SLE patients.

The advantage of this study is to evaluate simultaneously several possible risk factors for osteonecrosis in homogenous SLE patients regarding short disease duration. In fact, osteonecrosis seems to occur early in $\operatorname{SLE}(19,23,31)$ and the inclusion criteria of less than five years of disease duration might have minimized the effect of other confounding variables. In addition, since osteonecrosis predilection for sex is still controversial $(31,40,41)$, the study design including only female patients, excluded this possible gender influence.

Moreover, osteonecrosis diagnosis was confirmed and excluded herein by MRI, which is the gold standard method for early evaluation of bone marrow changes indicative of osteonecrosis (34-36) and has a good correlation with histology (34-36). The great variability in the results of previous studies regarding osteonecrosis risk factors could be explained by the use of other less sensitive screening diagnostic procedures such as clinical symptoms, bone scintigraphy and/or conventional radiographic images $(3-14,16,20-24,26,27,30,32)$.

Disruption of vascular supply has been proposed as the major underlying triggering event of non-traumatic osteonecrosis (2). Altered hemostasis leading to thrombosis and embolism is thought to play a role in this process. However, few studies have analyzed coagulation factors in SLE 
patients with osteonecrosis $(8,12,30)$. Interestingly, this complication has been reported in $20 \%$ of primary antiphospholipid syndrome (29), although the association with antiphospholipid antibodies is still controversial $(8,22,32)$. We therefore excluded patients with established antiphospholipid syndrome in order to avoid this known risk factor. Interestingly, the particular association with the hallmark antibodies of this syndrome was not confirmed in the present study. Similarly, there were no differences concerning thrombophilia and hypofibrinolysis abnormalities between the two groups. Moreover, hereditary procoagulant abnormalities, such as factor $\mathrm{V}$ Leiden and prothrombin gene mutation, which are possible risk factors for osteonecrosis were not observed in this study $(42,43)$. However, the small sample size may preclude a definitive conclusion since these are uncommon abnormalities in the general population.

On the other hand, several investigators have suggested that steroid use is the major risk factor for osteonecrosis in SLE patients since the first report of Dubois and Cozen (3-23). Accordingly, we have observed a significant higher cumulative dose of GC in the previous year of osteonecrosis clinical diagnosis, but not with the total cumulative dose over the years. Supporting this finding, previous studies have demonstrated that osteonecrosis is detected by MRI very early after steroid therapy $(19,44)$. The lack of association of total cumulative dose over the years observed in the present study might be explained by the shorter disease duration of 
patients with osteonecrosis compared to patients without this complication, although this difference did not reach statistical significance.

It is also important to emphasize that the incidence of osteonecrosis is low when GC is the only risk factor, reinforcing the possible relevance of other contributing factors in lupus. Indeed, Colwell et al did not find a direct relationship between GC dosage and the development of femoral head osteonecrosis in 1420 hip-years at 10-year follow up of asthma or inflammatory arthritis patients (45).

In this regard, the most relevant aspect raised by the multifactorial analysis performed herein is the role of disease activity as a significant factor for the development of osteonecrosis. Supporting this finding, Mok et al., observed that patients who require an initial high-dose steroid for disease control are at risk of osteonecrosis (9). The lack of association with SLEDAI reported by these authors is probably due to the fact that this measurement was performed at a single point in time.

A relevant issue concerning SLEDAI measurement is raised by the present work. The lack of association with remote SLEDAI reinforces the importance of evaluating flares close to osteonecrosis onset. On the other hand, our data also suggest that this complication is a process overtime which does not occur solely at the moment clinical ON onset.

In this regard, no association of osteonecrosis and the adjusted mean SLEDAI score of an average length of follow up of 6.9 years was reported by Ibanez et al (31). This discrepancy might be explained by the attenuation 
of higher disease activity scores in the previous year of osteonecrosis clinical diagnosis by the other years with lower SLEDAIs.

This multifactorial study provides therefore evidence that disease activity in the previous year of osteonecrosis clinical diagnosis is the main predictor factor for the development of this complication in early SLE. The consequent use of high dose of GC in the same period has certainly a synergistic role to the event. 


\section{REFERENCES}

1. Mont MA, Carbone JJ, Fairbank AC. Core decompression versus nonoperative management for osteonecrosis of the hip. Clin Orthop Relat Res 1996; 324: 169-178.

2. Ficat RP. Idiopathic bone necrosis of the femoral head. J Bone Joint Surg 1985; 67B: 3-9.

3. Dubois EL, Cozen L. Avascular (aseptic) bone necrosis associated with systemic lupus erythematosus. JAMA 1960; 174: 966-971.

4. Zizic TM, Marcoux C, Hungerford DS, Dansereau JV, Stevens MB. Corticosteroid therapy associated with ischemic necrosis of bone in systemic lupus erythematosus. Am J Med 1985; 79: 596-604.

5. Weiner ES, Abeles M. Aseptic necrosis and glucocorticosteroids in systemic lupus erythematosus: a reevaluation. J Rheumatol 1989; 16: 604-608.

6. Massardo L, Jacobelli S, Leissner M, Gonzalez M, Villarroel L, Rivero S. High-dose intravenous methylprednisolone therapy associated with osteonecrosis in patients with systemic lupus erythematosus. Lupus 1992; 1: 401-405.

7. Migliaresi S, Picillo $U$, Ambrosone $L$, et al. Avascular osteonecrosis in patients with SLE: relation to corticosteroid therapy and anticardiolipin antibodies. Lupus 1994; 3: 37-41. 
8. Mont MA, Glueck $\mathrm{CJ}$, Pacheco $\mathrm{IH}$, Wang $\mathrm{P}$, Hungerford DS, Petri M. Risk factors for osteonecrosis in systemic lupus erythematosus. J Rheumatol 1997; 24: 654-662.

9. Mok CC, Lau CS, Wong RW. Risk factors for avascular bone necrosis in systemic lupus erythematosus. Br J Rheumatol 1998; 37: 895-900.

10. Zizic TM, Hungerford DS, Stevens MB. Ischemic bone necrosis in systemic lupus erythematosus. The early diagnosis of ischemic necrosis of bone. Medicine 1980; 59: 134-142.

11. Abeles M, Urman JD, Rothfield NF. Aseptic necrosis of bone in systemic lupus erythematosus. Relationship to corticosteroid therapy. Arch Inter Med 1978; 138: 750-754.

12. Sheik JS, Retzinger GS, Hess EV. Association of osteonecrosis in systemic lupus erythematosus with abnormalities of fibrinolysis. Lupus 1998; 7: 42-48.

13. Rascu A, Manger K, Kraetsch HG, Kalden JR, Manger B. Osteonecrosis in systemic lupus erythematosus, steroid-induced or a lupusdependent manifestation? Lupus 1996; 5: 323-327.

14. Klippel JH, Gerberg LH, Pollak L, Decker JL. Avascular necrosis of bone in systemic lupus erythematosus: Silent symmetric osteonecrosis. Am J Med 1979; 67: 83-87.

15. Zizic TM. Avascular necrosis of bone. Curr Opin Rheumatol 1990; 2: 26-37. 
16. Bergstein JM, Wiens C, Fish AJ, Vernier RL, Michael A. Avascular necrosis of bone in systemic lupus erythematosus. J Pediatr 1974; 85: $31-35$.

17. Nagasawa $\mathrm{K}$, Tsukamoto $\mathrm{H}$, Tada $\mathrm{Y}$, et al. Imaging study on the mode of development and changes in avascular necrosis of the femoral head in systemic lupus erythematosus: long term observations. $\mathrm{Br} \mathrm{J}$ Rheumatol 1994; 33: 343-347.

18. Aranow C, Zelicof S, Leslie D, et al. Clinically occult avascular necrosis of the hip in systemic lupus erythematosus. J Rheumatol 1997; 24: 2318-2322.

19. Oinuma K, Harada $Y$, Nawata $Y$, et al. Osteonecrosis in patients with systemic lupus erythematosus develops very early after starting high dose corticosteroid treatment. Ann Rheum Dis 2001; 60: 1145-1148.

20. Gladman DD, Urowitz MB, Chaudry-Ahluwalia V, Hallet DC, Cook RJ. Predictive factors for symptomatic osteonecrosis in patients with systemic lupus erythematosus. J Rheumatol 2001; 28: 761-765.

21. Nagasawa K, Ishii YI, Mayumi T, et al. Avascular necrosis of bone in systemic lupus erythematosus: possible role of haemostatic abnormalities. Ann Rheum Dis 1989; 48: 672-676.

22. Houssiau FA, Toukap NA, Depresseux G, et al. Magnetic resonanceimaging-detected avascular osteonecrosis in systemic lupus erythematosus: lack of correlation with antiphospholipid antibodies. Br J Rheumatol 1998; 37: 448-453. 
23. Nagasawa K, Tada Y, Koarada S, et al. Very early development of steroid-associated osteonecrosis of femoral head in systemic lupus erythematosus: prospective study by MRI. Lupus 2005; 14: 385-390.

24. Nilsen KH. Systemic lupus erythematosus and avascular bone necrosis. N Z Med J 1977; 8: 472-475.

25. Hungerford DS, Zizic TM. The treatment of ischemic necrosis of bone in systemic lupus erythematosus. Medicine 1980; 59: 143-148.

26. Abeles M, Weiner ES, Parke A, Wilson D. The association of osteonecrosis in SLE with anticardiolipin antibodies. Arthritis Rheum 1991; 34(suppl): R39.

27. Asherson RA, Liote F, Page B, et al. Avascular necrosis of bone and antiphospholipid antibodies in systemic lupus erythematosus. J Rheumatol 1993; 20: 284-288.

28. Seleznic MJ, Silveira LH, Espinoza LR. Avascular necrosis associated with anticardiolipin antibodies. J Rheumatol 1991;18: 1416-1417.

29. Tektonidou MG, Malagari K, Vlachoyiannopoulos PG, Kelekis DA, Moutsopoulos HM. Asymptomatic avascular necrosis in patients with primary antiphospholipid syndrome in the absence of corticosteroid use: a prospective study by resonance imaging. Arthritis Rheum 2003; 48: 732-736.

30. Jones LC, Mont MA, Le TB, Petri M, Hungerford DS, Wang P, Glueck CJ. Progoagulants and Osteonecrosis. J Rheumatol 2003; 30: 783-791. 
31. Ibanez D, Gladman DD, Urowitz MB. Adjusted mean Systemic Lupus Erythematosus Disease Activity Index-2K is a predictor of outcome in SLE. J Rheumatol 2005; 32: 824-827.

32. Mok MY, Farewell VT, Isenberg DA. Risk factors for avascular necrosis of bone in patients with systemic lupus erythematosus: is there a role for antiphospholipid antibodies? Ann Rheum Dis 2000; 59: 462-467.

33. Halland AM, Klemp P, Botes D, Van Heerden BB, Loxton A, Scher AT. Avascular necrosis of the hip in systemic lupus erythematosus: the role of magnetic resonance imaging. $\mathrm{Br}$ J Rheumatol 1993; 32: 972-976.

34. Kalunian KC, Hahn BH, Bassett L. Magnetic resonance imaging identifies early femoral head ischemic necrosis in patients receiving systemic glucocorticoid therapy. J Rheumatol 1989; 16: 959-963.

35. Mitchell DG, Rao VM, Dalinka MK, et al. Femoral head avascular necrosis: correlation of MR imaging, radiographic staging, radionuclide imaging, and clinical findings. Radiol 1987; 162: 709-715.

36. Markisz JA, Knowles RJ, Altchek DW, Schneider R, Whalen J, Cahill PT. Segmenal patterns of avascular necrosis of the femoral heads: early detection with MR imaging. Radiol 1987; 162: 717-720.

37. Hochberg MC. Updating the American College of Rheumatology revised criteria for the classification of systemic lupus erythematosus. Arthritis Rheum 1997; 40: 1725 (letter). 
38. Bombardier C, Gladman DD, Urowitz MB, Caron D, Chang $\mathrm{CH}$, and the Committee on Prognosis Studies in SLE. Derivation of the SLEDAI: a disease activity index for lupus patients. Arthritis Rheum 1992; 35: 630-640.

39. Gladman D, Ginzler E, Goldsmith C, et al. The development and initial validation of the Systemic Lupus International Collaborating Clinics/American College of Rheumatology damage index for systemic lupus erythematosus. Arthritis Rheum 1996; 39: 363-369.

40. Talamo G, Angtuaco E, Walker RC, et al. Avascular necrosis of femoral and/or humeral heads in multiple myeloma: results of a prospective study of patients treated with dexamethasone-based regimes and highdose chemotherapy. J Clin Oncol 2005; 23: 5217-5223.

41. Schulte CM, Beelen DW. Avascular osteonecrosis after allogenic hematopoietic stem-cell transplantation: diagnosis and gender matter. Transplantation. 2004; 78: 1055-1063.

42. Bjorkman A, Burtscher IM, Svensson PJ, Hillarp A, Besjakov J, Benoni G. Factor V Leiden and prothrombin 20210A gene mutation and osteonecrosis of the knee. Arch Orthop Trauma Surg 2005; 125: 51-55.

43. Bjorkman A, Svensson PJ, Hillarp A, Burtscher IM, Runow A, Benoni G. Factor $\mathrm{V}$ Leiden and prothrombin gene mutation: risk factors for osteonecrosis of femoral head in adults. Clin Orthop Relat Res 2004; 425: $168-172$. 
44. Sakamoto M, Shimizu K, Lida S, Akita T, Moriya H, Nawata Y. Osteonecrosis of the femoral head: a prospective study with MRI. J bone Joint Surg Br 1997; 79: 213-219.

45. Colwell CW Jr, Robinson CA, Stevenson DD, Vint VC, Morris BA. Osteonecrosis of the femoral head in patients with inflammatory arthritis or asthma receiving corticosteroid therapy. Orthopedics 1996; 19: $941-946$. 
Table1: Clinical features in SLE patients at osteonecrosis clinical diagnosis (ON group) and SLE patients without osteonecrosis at study entry (CONTROL group).

\begin{tabular}{|c|c|c|c|}
\hline & $\begin{array}{l}\text { ON group } \\
(n=10)\end{array}$ & $\begin{array}{c}\text { CONTROL } \\
\text { group } \\
(n=36)\end{array}$ & $p$ \\
\hline Vasculitis, \% & 30 & 22 & 0.61 \\
\hline Raynaud, \% & 30 & 58 & 0.11 \\
\hline Livedo reticularis, \% & 30 & 19 & 0.47 \\
\hline Cushing, \% & 100 & 82 & 0.31 \\
\hline $\mathrm{BMI}\left(\mathrm{Kg} / \mathrm{m}^{2}\right)$ & $24.0 \pm 3.5$ & $25.0 \pm 4.9$ & 0.89 \\
\hline \multicolumn{4}{|l|}{ Disease activity (SLEDAI $\geq 8$ ) } \\
\hline ON clinical diagnosis , $\%$ & 10 & 11 & 1.00 \\
\hline Previous year, \% & 60 & 19 & 0.01 \\
\hline Remote $\left(13-24^{\text {th }} \text { mo. prior ON }\right)^{*}, \%$ & 28 & 50 & 0.23 \\
\hline \multicolumn{4}{|l|}{ Disease damage } \\
\hline SLICC index $>0, \%{ }^{*}$ & 20 & 36 & 0.33 \\
\hline \multicolumn{4}{|c|}{$\begin{array}{l}\text { Values are expressed as mean } \pm \text { SD or percentages; g: grams; NA: not } \\
\text { applicable. }\end{array}$} \\
\hline
\end{tabular}


Table 2: Treatment in SLE patients at osteonecrosis clinical diagnosis (ON group) and SLE patients without osteonecrosis at study entry (CONTROL group).

\begin{tabular}{lccc}
\hline & $\begin{array}{c}\text { ON group } \\
(\mathrm{n}=10)\end{array}$ & $\begin{array}{c}\text { CONTROL } \\
\text { group }(\mathrm{n}=36)\end{array}$ & $p$ \\
\hline Glucocorticoid treatment & & & \\
Previous year $(\mathrm{mg})$ & $10,503 \pm 5,100$ & $7,050 \pm 5,699$ & $\mathbf{0 . 0 4}$ \\
Previous $13^{\text {th }}-24^{\text {th }}$ mo. $(\mathrm{mg})$ & $4,470 \pm 4,428$ & $5,017 \pm 5,005$ & 0.75 \\
Total cumulative $(\mathrm{mg})$ & $17,823 \pm 8,386$ & $20,924 \pm 10,772$ & 0.40 \\
ON clinical onset (mg/day) & $20 \pm 14$ & $19 \pm 21$ & 0.42 \\
Immunosuppressive ${ }^{*}, \%$ & 70 & 67 & 1.00 \\
Chloroquine, \% & 80 & 86 & 0.64 \\
\hline
\end{tabular}

Values are expressed as means \pm SD or percentages; mg: milligrams.

* Use ever 
Table 3: Lipoprotein profile in SLE patients at osteonecrosis clinical diagnosis (ON group) and SLE patients without osteonecrosis at study entry (CONTROL group).

\begin{tabular}{lccc}
\hline & $\begin{array}{c}\text { ON group } \\
(\mathrm{n}=10)\end{array}$ & $\begin{array}{c}\text { CONTROL group } \\
(\mathrm{n}=36)\end{array}$ & $p$ \\
\hline Total cholesterol $(\mathrm{mg} / \mathrm{ml})$ & $202.9 \pm 91.0$ & $180.0 \pm 42.3$ & 0.89 \\
LDL-fraction $(\mathrm{mg} / \mathrm{ml})$ & $112.3 \pm 51.1$ & $99.7 \pm 31.9$ & 0.75 \\
HDL-fraction $(\mathrm{mg} / \mathrm{ml})$ & $47.9 \pm 21.8$ & $55.5 \pm 17.5$ & 0.26 \\
Triglycerides $(\mathrm{mg} / \mathrm{ml})$ & $127.2 \pm 64.1$ & $126.0 \pm 60.9$ & 0.84 \\
\hline
\end{tabular}

Values are expressed as means \pm SD. 
Table 4: Laboratory data at study entry for thrombophilia and hypofibrinolysis in SLE patients with osteonecrosis (ON group) and SLE patients without osteonecrosis (CONTROL group)

\begin{tabular}{lccc}
\hline & $\begin{array}{c}\text { ON group } \\
(\mathrm{n}=10)\end{array}$ & $\begin{array}{c}\text { CONTROL group } \\
(\mathrm{n}=36)\end{array}$ & $p$ \\
\hline LA, \% & 0 & 8 & 0.59 \\
ACL IgG, \% & 10 & 3 & 0.39 \\
ACL IgM, \% & 10 & 3 & 0.39 \\
High Factor VIII, \% & 60 & 66 & 0.69 \\
High Homocysteine, \% & 40 & 42 & 0.92 \\
Lp (a) > 30mg/dl, \% & 50 & 44 & 0.74 \\
Low AT III, \% & 10 & 8 & 1.00 \\
Low PC, \% & 20 & 6 & 0.20 \\
Low PS, \% & 20 & 3 & 0.11 \\
\hline $\begin{array}{l}\text { Values are expressed } \\
\text { anticardiolipin antibodies, }\end{array}$ & percentages. & LA: & lupus \\
protein C, PS: protein S. & Lipoprotein & a, AT: antithrombin, & PC: \\
\end{tabular}

